\title{
O USO DE APARELHOS DE MICRO-ONDAS DOMÉSTICOS EM AULAS EXPERIMENTAIS DE QUÍMICA ORGÂNICA: NITRAÇÃO DE SALICILALDEÍDO
}

\section{Eurídes Francisco Teixeira, Ana Paula Bernardo dos Santos*, Renato Saldanha Bastos e Angelo C. Pinto}

Departamento de Química Orgânica, Instituto de Química, Bl. A, Centro de Tecnologia, Cidade Universitária, Universidade Federal do Rio de Janeiro, 21949-900 Rio de Janeiro - RJ, Brasil

Arthur Eugen Kümmerle

Departamento de Fármacos, Faculdade de Farmácia, Cidade Universitária, Universidade Federal do Rio de Janeiro, 21941-902

Rio de Janeiro - RJ, Brasil

Roberto Rodrigues Coelho

Centro de Tecnologia Mineral, Cidade Universitária, Universidade Federal do Rio de Janeiro, 21941-590 Rio de Janeiro - RJ, Brasil

Recebido em 13/10/09; aceito em 3/4/10; publicado na web em 9/8/10

\begin{abstract}
THE USE OF DOMESTIC MICROWAVE OVEN IN EXPERIMENTAL CLASSES OF ORGANIC CHEMISTRY: SALICYLALDEHYDE NITRATION. The use of microwave in chemistry has known benefits over conventional heating methods, e.g. reduced reaction times, chemical yield improvement and the possibility if reducing or eliminating the use of organic solvents. We describe herein a procedure for the nitration of salicylaldehyde in water using a domestic microwave oven, which can be used as an experiment in the undergraduate chemistry laboratory. The experiment involves safe and rapid preparation and identification of the position isomers by thin layer chromatography and $1 \mathrm{H}$ NMR, or by their melting points.
\end{abstract}

Keywords: microwave; nitration; salicylaldehyde.

\section{INTRODUÇÃO}

Desde a $2^{\circ}$ Guerra Mundial os aparelhos que emitem radiação de micro-ondas passaram a estar presentes em nosso cotidiano. Inicialmente, funcionavam como radar (Radio Detection and Ranging) para detectar aeronaves inimigas. As micro-ondas, ao serem refletidas pelo objeto procurado, eram detectadas pelo radar que fornecia sua posição, forma, velocidade e direção. ${ }^{1}$

Em 1947, Percy L. Spencer fez alterações nestes aparelhos e a companhia Raytheon apresentou o primeiro forno de micro-ondas para aquecer ou descongelar alimentos. Chamado de Radarange, o micro-ondas possuía $1,5 \mathrm{~m}$ de altura, pesava cerca de $340 \mathrm{~kg}$ e custava entre US\$2.000 e 3.000. Hoje, os fornos de micro-ondas domésticos são bem mais leves e acessíveis. ${ }^{1}$

As micro-ondas (MO) são ondas eletromagnéticas geradas por um magnetron situadas na região do espectro eletromagnético, entre a radiação do infravermelho e as ondas de rádio. A frequência das micro-ondas oscila entre $300 \mathrm{MHz}\left(300\right.$ x 10 $\left.10^{6} \mathrm{~Hz}\right)$ e $300 \mathrm{GHz}(300 \mathrm{x}$ $10^{9} \mathrm{~Hz}$ ), com comprimentos de onda de $1 \mathrm{~mm}$ a $1 \mathrm{~m}$, respectivamente. A frequência utilizada em fornos comerciais é de 2,450 GHz. ${ }^{2,3}$

$\mathrm{O}$ aquecimento através das micro-ondas ocorre por dois mecanismos, polarização dipolar e condução iônica. As micro-ondas ao penetrarem em materiais que contêm moléculas polares, provocam o alinhamento dos pólos destas moléculas com o campo eletromagnético aplicado. A responsável pelo efeito descrito é a componente do campo elétrico, ao invés do campo magnético. Com a remoção do campo eletromagnético, as moléculas voltam ao estado desordenado, fazendo com que a energia absorvida para a orientação seja dissipada na forma de calor. Este processo ocorre em ciclos devido à oscilação do campo eletromagnético. ${ }^{1-6}$

A capacidade de um material ou solvente converter energia de micro-ondas em calor depende da frequência de relaxação do material e da constante dielétrica do solvente. Quanto maior o dipolo elétrico,

*e-mail: apcanela@yahoo.com.br mais intensa será a orientação molecular e quanto maior a constante dielétrica, maior será a quantidade de energia armazenada. A constante dielétrica se relaciona à tangente de perda, que é a razão entre a constante dielétrica e o fator de perda. Este último mede a eficiência da conversão de energia eletromagnética em calor. Em geral, para frequências padrões de operação, altos valores de tangente de perda são requeridos para eficientes absorções de calor. ${ }^{1,4,5,7}$

Tabela 1. Valores de constantes dielétricas e fatores de perda de solventes usados em sínteses orgânicas promovidas por micro-ondas

\begin{tabular}{|c|c|c|c|c|c|}
\hline Solvente & $\begin{array}{l}\text { Constante } \\
\text { dielétrica }\end{array}$ & $\begin{array}{c}\text { Fator de } \\
\text { perda }\end{array}$ & Solvente & $\begin{array}{l}\text { Constante } \\
\text { dielétrica }\end{array}$ & $\begin{array}{c}\text { Fator de } \\
\text { perda }\end{array}$ \\
\hline Hexano & 1,9 & 0,020 & $\begin{array}{l}\text { Acetato de } \\
\text { etila }\end{array}$ & 6,2 & 0,059 \\
\hline Tolueno & 2,4 & 0,040 & Acetona & 20,6 & 0,054 \\
\hline $\begin{array}{l}\text { Tetracloreto de } \\
\text { carbono }\end{array}$ & 2,2 & - & Etanol & 24,6 & 0,941 \\
\hline Clorofórmio & 4,8 & 0,091 & Metanol & 32,7 & 0,659 \\
\hline Diclorometano & 9,1 & 0,042 & Acetonitrila & 36,0 & 0,062 \\
\hline $\begin{array}{l}\text { Tetra-hidrofu- } \\
\text { rano }\end{array}$ & 7,6 & 0,047 & Água & 80,4 & 0,123 \\
\hline
\end{tabular}

Somente moléculas polares absorvem a energia das micro-ondas. Desta maneira, recipientes que não absorvem micro-ondas como quartzo, teflon e cerâmicas não são aquecidos, o que representa uma grande economia de energia. ${ }^{6}$

Em 1986, Gedye e colaboradores ${ }^{8}$ e Giguere e colaboradores ${ }^{9}$ demonstraram que muitas reações orgânicas poderiam ser feitas com aparelhos de MO domésticos como fonte de aquecimento e, mais recentemente, muitas reações têm sido realizadas em fornos de microondas dedicados. Alguns dos benefícios do uso das $\mathrm{MO}$ em reações orgânicas são o aumento do rendimento e pureza (devido à redução de reações colaterais) e a redução significativa do tempo de reação. Outra vantagem é que algumas reações em micro-ondas podem ser 
feitas sem solventes, com menor desperdício de reagentes, menor decomposição térmica e maior seletividade., ${ }^{1,-11}$

Diferentemente do que ocorre quando o aquecimento é realizado por convecção, em que a energia é transferida lentamente do recipiente da reação para a solução, nas reações feitas em fornos de micro-ondas os reagentes absorvem diretamente a energia gerada pelo aparelho. ${ }^{7}$ A comparação do efeito térmico em micro-ondas e em sistema convencional (banho de óleo) realizada por La Hoz e colaboradores demonstrou que os meios reacionais aquecidos pelo micro-ondas sofrem aquecimento rápido e uniforme, em contraste com os aquecidos convencionalmente, onde o aquecimento é mais lento e concentrado nas fontes de convecção. ${ }^{12}$

Atualmente existem reatores de micro-ondas feitos especificamente para reações orgânicas. No entanto, devido ao seu alto custo, os fornos micro-ondas caseiros podem e são bastante utilizados para este fim. Estas reações em fornos micro-ondas convencionais são normalmente conduzidas em Erlenmeyer, utilizando-se um funil no topo para evitar a perda do solvente. O solvente utilizado deve ser polar e com ponto de ebulição no mínimo 20 a $30{ }^{\circ} \mathrm{C}$ superior à temperatura da reação desejada. ${ }^{13}$

A Tabela 2 traça uma comparação entre os tempos de reação e os rendimentos obtidos em reações orgânicas convencionais e em microondas, mostrando a eficiência da segunda em processos de síntese.

Devido às vantagens das reações realizadas em fornos de microondas, o número de publicações em livros e artigos científicos tem crescido expressivamente. Kappe e Dallinger demonstram que entre 2008 e 2009 foram mais de 900 artigos publicados em 50 jornais, associados a processos controlados em reatores, enquanto que entre 2001 e 2002 eram menos de 100. Além disto, nesta revisão são relatados exemplos de reações com bons rendimentos, tais como, reação de Mizoroki-Heck, Suzuki-Miyauara, Buchwald-Hartwig, Mitsunobu, condensações de Ullmann, rearranjos de Claisen, cicloadições, reduções, hidrogenações, metáteses, glicosilações, carbonilações, alquilações, substituições nucleofílicas aromáticas, adições e eliminações, substituições, aminações redutivas, formações de ésteres e amidas, reações radicalares, reações de proteção e desproteção e síntese de heterociclos. ${ }^{14}$

A variável tempo é cada vez mais importante no universo da Química e, por isso, o uso de fornos de micro-ondas como fonte de aquecimento de reações orgânicas vem ganhando mais e mais espaço.

Neste trabalho é proposta a nitração do salicilaldeído com solução de $\mathrm{HNO}_{3}$ a $10 \%$, usando como fonte de aquecimento um forno de micro-ondas doméstico.

\section{NITRAÇÃO DO SALICILALDEÍDO}

As reações de nitração de substratos aromáticos estão entre as mais comuns nas disciplinas experimentais dos cursos de Graduação em Química e de áreas afins. ${ }^{15}$ Geralmente, as reações de nitração, utilizadas como exemplo de reações de substituição eletrofílica aromática, são feitas a partir de um substrato aromático e uma mistura de ácido sulfúrico $98 \%$ e ácido nítrico $65 \%$ (mistura sulfonítrica). Inicialmente, ocorre uma reação ácido-base entre $\mathrm{H}_{2} \mathrm{SO}_{4}$ e $\mathrm{HNO}_{3}$ que leva à formação do íon nitrônio $\left(\mathrm{NO}_{2}^{+}\right)$, espécie eletrofílica responsável pela reação de substituição eletrofílica aromática. ${ }^{16}$ Contudo, tais reações não são consideradas limpas para o meio ambiente. Adicionalmente, a nitração de substratos utilizando a mistura sulfonítrica, em processos industriais, exige um excesso de ácido sulfúrico para compensar a formação de água como subproduto. Desta maneira, a alta acidez acarreta, inevitavelmente, a corrosão do reator e o risco de acidentes. ${ }^{17}$

A busca por processos sintéticos seguros e mais limpos, do ponto de vista ambiental, tem levado cada vez mais à utilização da água como solvente devido a vantagens como o seu baixo custo, não ser inflamável, ausência de toxicidade e por ser ambientalmente segura. O uso da água como solvente é um dos tópicos importantes para a discussão, em cursos de graduação, dos conceitos de química limpa. ${ }^{18}$

Desta forma, seguindo diversos trabalhos que têm descrito o uso de novas abordagens sintéticas no ensino experimental de Química Orgânica, ${ }^{19}$ este trabalho propõe a síntese dos isômeros 5-nitro-salicilaldeído e 3-nitro-salicilaldeído através da nitração do salicilaldeído com solução aquosa de $\mathrm{HNO}_{3}$ diluída, utilizando a radiação de microondas. Esta é uma boa oportunidade para os alunos obterem isômeros de posição em uma única etapa, os separarem e os identificarem através dos seus respectivos pontos de fusão e espectros de $\mathrm{RMN}{ }^{1} \mathrm{H}$.

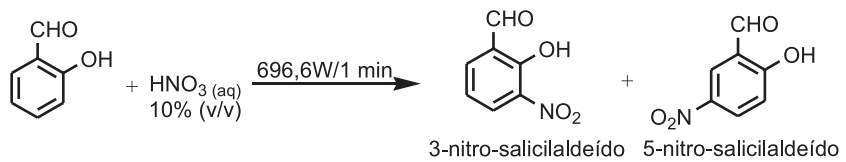

Figura 1. Reação de nitração do salicilaldeído em micro-ondas doméstico

Tabela 2. Comparação entre reações com aquecimento convencional e em forno de micro-ondas

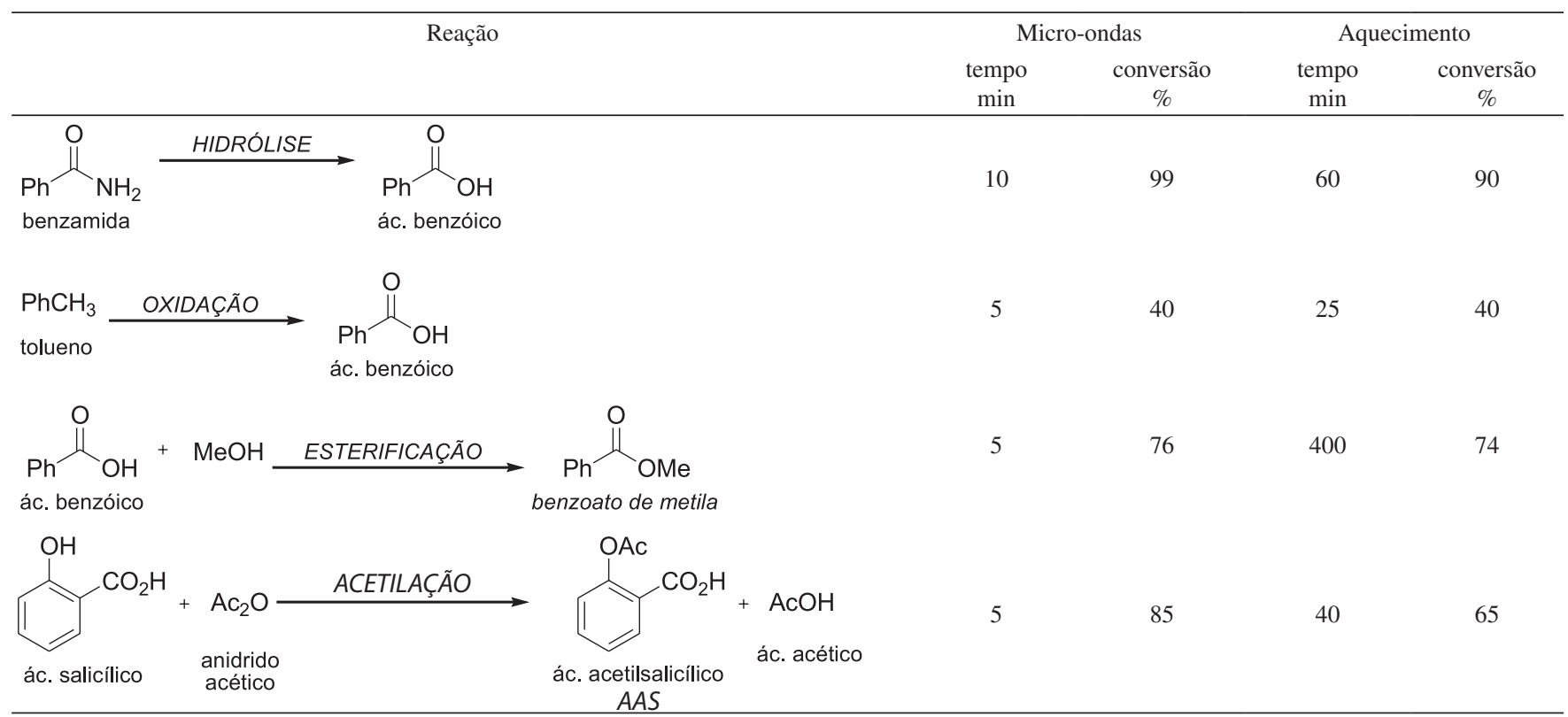




\section{Procedimento}

Em um Erlenmeyer de $125 \mathrm{~mL}$, pesaram-se $4 \mathrm{~g}$ de salicilaldeído e adicionaram-se $30 \mathrm{~mL}$ de solução aquosa de ácido nítrico PA 10\% v/v. O Erlenmeyer foi agitado manualmente durante alguns segundos e, em seguida, após adaptação de um funil de colo curto $(\mathrm{ca} .3,0 \mathrm{~cm}$ de colo, $3,5 \mathrm{~cm}$ de diâmetro na abertura superior e $1 \mathrm{~cm}$ na abertura inferior), colocado em um forno de micro-ondas doméstico no nível 8, potência de $696,6 \mathrm{~W}$, durante $60 \mathrm{~s}$. Todo o procedimento deve ser realizado em capela, sob exaustão, por motivos de segurança e da liberação de vapores.

O Erlenmeyer foi retirado do forno de micro-ondas, deixado resfriar por cerca de $5 \mathrm{~min}$ e, em seguida, levado a um recipiente com banho de gelo picado. Imediatamente, houve a precipitação de um sólido amarelo, que foi filtrado a vácuo e lavado com água destilada gelada. A formação dos produtos nitrados pôde ser observada por cromatografia em camada fina (CCF) seguida de visualização em câmara de ultravioleta ou revelação com iodo, após uma corrida cromatográfica utilizando uma mistura de hexano:acetato de etila (7:3) como eluente.

O precipitado obtido foi solubilizado em cerca de $80 \mathrm{~mL}$ de solução de $\mathrm{NaOH}$ 1,0 mol L-1 em um Becker de $250 \mathrm{~mL}$, sendo necessário agitação e aquecimento até a dissolução completa do precipitado amarelo. Esta solução, vermelho escura, foi resfriada em banho de gelo durante 30 min e o precipitado obtido foi filtrado (reservando-se o filtrado), lavado com água destilada gelada, depois com ca. $40 \mathrm{~mL}$ de uma solução gelada de ácido clorídrico PA $10 \%$ e, novamente, com água destilada. Este produto foi inicialmente identificado como o 5-nitro-salicilaldeído através da comparação de seu ponto de fusão experimental (PF exp. $125^{\circ} \mathrm{C}$ ) com o valor (PF lit. $126^{\circ} \mathrm{C}$ ) descrito na literatura. ${ }^{20}$ Ao filtrado reservado foram adicionados $c a .50 \mathrm{~mL}$ de solução de ácido clorídrico PA $10 \%$ até completa precipitação de um material amarelado que, em seguida, foi filtrado, lavado com água destilada gelada e seco à temperatura ambiente. Este sólido amarelado foi identificado como o 3-nitro-salicilaldeído através de seu ponto de fusão (PF exp. $102{ }^{\circ} \mathrm{C} / \mathrm{PF}$ lit. $\left.109^{\circ} \mathrm{C}\right) .{ }^{20}$

\section{Dados dos aparelhos}

O forno micro-ondas utilizado foi da marca Brastemp, $110 \mathrm{~V}, 27$ L, sob a frequência de $2450 \mathrm{MHz}$. Deve-se ter cuidado com o uso de aparelhos de micro-ondas, devido a sua radiação, porque líquidos podem sofrer superaquecimento, recipientes fechados podem explodir, metais podem gerar centelhamentos e/ou explosões, que podem levar a queimaduras sérias. Por isto, o equipamento deve ser usado em capelas e somente deve ser aberto após desligado.

Para a obtenção dos espectros de $\mathrm{RMN}{ }^{1} \mathrm{H}$ e ${ }^{13} \mathrm{C}, 30 \mathrm{mg}$ das amostras foram dissolvidas em $0,6 \mathrm{~mL}_{\text {de }} \mathrm{CDCl}_{3}$, à $25^{\circ} \mathrm{C}$, em tubos de $5 \mathrm{~mm}$ de diâmetro.

Os espectros de RMN foram obtidos em um espectrômetro Bruker, modelo Avance, operando a $200 \mathrm{MHz}$, e estão disponíveis no material suplementar.

As análises de CGAR-EM foram realizadas em cromatógrafo Agilent modelo 6890, acoplado a um detector de massas Agilent modelo 5973, com ionização por impacto de elétrons a $70 \mathrm{eV}$ e analisador do tipo quadrupolo. A coluna capilar utilizada foi DB-1 HT (J\&W) $30 \mathrm{~m} \times 0,25 \mathrm{~mm} \times 0,10 \mu \mathrm{m}$ de espessura de fase. $\mathrm{O}$ gás de arraste utilizado foi hélio $\left(0,8 \mathrm{~mL} \mathrm{~min}^{-1}\right)$ e a pressão na cabeça da coluna foi de 8 psi. A amostra foi injetada com volume de $0,1 \mu \mathrm{L}$ com divisão de fluxo de 20:1. As temperaturas iniciais do forno, injetor e detetor foram de 100,280 e $280{ }^{\circ} \mathrm{C}$, respectivamente. A rampa empregada foi de $4{ }^{\circ} \mathrm{C} \cdot \mathrm{min}^{-1}$, mantendo-se o aquecimento por 5,0 min na temperatura final de $200{ }^{\circ} \mathrm{C}$. O tempo total de corrida foi de $25,0 \mathrm{~min}$ e o cromatograma foi obtido no modo de varredura de íons totais (scan).
Para a determinação dos valores de $\mathrm{pKa}$ dos isômeros 3 e 5-nitrosalicilaldeído, utilizou-se o programa Moka pKa. O programa prevê valores de $\mathrm{pKa}$ em meio aquoso e baseia-se num conjunto de modelos estatísticos combinados a uma base de dados de mais de 25.000 valores de $\mathrm{pKa}$.

\section{RESULTADOS E DISCUSSÃO}

Dentre os diferentes parâmetros reacionais testados, observou-se que a nitração do salicilaldeído ocorreu com melhores rendimentos no nível 8 do aparelho, potência de 696,6 W (calculada como indicado no material suplementar), por $60 \mathrm{~s}$, obtendo-se uma mistura isomérica de 3 e 5-nitro-salicilaldeído em $61 \%$ de rendimento (3,3 g) global. Este rendimento é próximo ao da nitração do salicilaldeído descrita por Bose e colaboradores. ${ }^{21} \mathrm{~A}$ formação dos produtos e a evolução da reação puderam ser acompanhadas por cromatografia em camada fina (CCF) e posterior visualização em câmara de ultravioleta ou revelação com iodo. Após uma corrida cromatográfica utilizando como eluente uma mistura de hexano:acetato de etila (7:3), os produtos 5-nitro-salicilaldeído e 3-nitro-salicilaldeído foram observados como manchas com Rfs 0,6 e 0,5. Vale destacar que não foi observada a formação do produto dinitrado, que apresentaria um menor Rf devido a sua maior polaridade e maior peso molecular.

A caracterização dos isômeros foi feita por cromatografia com fase gasosa acoplada à espectrometria de massas. A comparação entre as áreas permitiu a identificação do percentual dos isômeros na mistura. A análise da mistura obtida logo após o isolamento da reação indicou dois picos com tempos de retenção de 10,06 e 10,61 min referentes ao 3-nitro-salicilaldeído (28\%) e 5-nitro-salicilaldeído (72\%), respectivamente. A proporção final dos isômeros 3-nitro-salicilaldeído e 5-nitro-salicilaldeído pôde também ser avaliada através da comparação da integração dos sinais referentes aos hidrogênios dos aldeídos de cada isômero por ressonância magnética nuclear de hidrogênio.

A cristalização seletiva dos isômeros em meio básico de $\mathrm{NaOH}$ 1 mol L ${ }^{-1}$ originou $1,35 \mathrm{~g}$ ( $25 \%$ de rendimento após recristalização) para o 5-nitro-salicilaldeído e $0,91 \mathrm{~g}$ (17\% de rendimento após recristalização) para o 3-nitro-salicilaldeído.

Os valores teóricos de pKa dos isômeros do 3 e 5-nitro-salicilaldeído (5,34 e 5,37, respectivamente), calculados pelo programa Moka pKa, são muito próximos. Desta forma, a adição de uma solução aquosa de $\mathrm{NaOH}(\mathrm{pH}=14)$ leva à completa formação de sais de sódio para ambos os isômeros. No entanto, a solubilidade destes sais em água é bastante diferente. Enquanto o sal sódico do 3-nitro-salicilaldeído possui grande solubilidade em água à temperatura ambiente, o fenolato do 5-nitro-salicilaldeído apresenta baixa solubilidade em solução aquosa, o que leva a sua precipitação seletiva em meio básico. A acidificação do filtrado, onde se encontra o 3-nitro-salicilaldeído, faz com que este volte a sua forma neutra, que apresenta baixa solubilidade em água, tornando-o insolúvel nestas condições e acarretando sua precipitação. ${ }^{22}$

A análise dos espectros de ressonância magnética nuclear de hidrogênio permitiu a identificação inequívoca dos compostos que se apresentavam puros e sem a presença do produto dinitrado. O RMN de $\mathrm{H}^{1}$ permitiu a caracterização do isômero 5-nitro-salicilaldeído como sendo o primeiro produto precipitado e o 3-nitro-salicilaldeído precipitado apenas após neutralização. Seus deslocamentos quími$\cos (\delta)$, multiplicidades $(m)$ e constantes de acoplamento $(J)$ estão descritos na Tabela 3.

\section{CONCLUSÃO}

A nitração do salicilaldeído com solução aquosa de ácido nítrico PA $10 \%$ v/v, feita em micro-ondas doméstico, ocorre em 60 s. Esta 

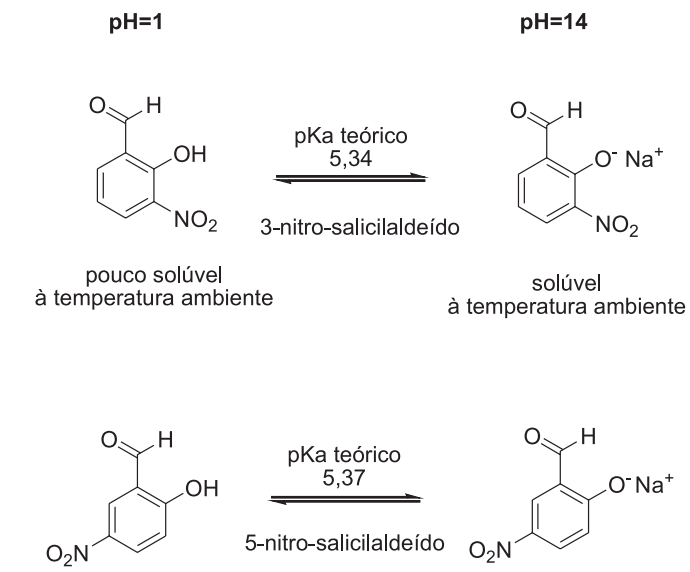

pouco solúvel à temperatura ambiente

pouco solúve à temperatura ambiente

Figura 2. Precipitação seletiva dos isômeros de nitro-salicilaldeído à temperatura ambiente

Tabela 3. Deslocamentos químicos ( $\delta$ ), multiplicidades (m) e constantes de acoplamentos $(J)$ de hidrogênios dos isômeros 3 e 5 -nitro-salicilaldeído<smiles>O=Cc1cccc([N+](=O)[O-])c1O</smiles>

3-nitro-salicilaldeído

3-nitro-salicilaldeído<smiles>O=Cc1cc([N+](=O)[O-])c([AsH])cc1O</smiles>

5-nitro-salicilaldeído

\begin{tabular}{ccccccc} 
Hidrogênio & $\delta(\mathrm{ppm})$ & $\mathrm{m}$ & $J(\mathrm{~Hz})$ & $\delta(\mathrm{ppm})$ & $\mathrm{m}$ & $J(\mathrm{~Hz})$ \\
\hline 3 & - & - & - & 7,13 & $\mathrm{~d}$ & 9,2 \\
4 & 8,11 & $\mathrm{dd}$ & 1,$7 ; 8,0$ & 8,41 & $\mathrm{dd}$ & 2,$8 ; 9,2$ \\
5 & 7,15 & $\mathrm{t}$ & 8,0 & - & - & - \\
6 & 8,35 & $\mathrm{dd}$ & 1,$7 ; 8,0$ & 8,57 & $\mathrm{~d}$ & 2,8 \\
$\mathrm{H}_{\text {aldoxila }}$ & 10,41 & $\mathrm{~s}$ & - & 10,00 & $\mathrm{~s}$ & - \\
$\mathrm{H}_{\text {fenol }}$ & 11,45 & $\mathrm{~s}$ & - & 11,60 & $\mathrm{~s}$ & - \\
\hline
\end{tabular}

reação tem grande relevância em disciplinas experimentais de cursos de graduação, por abordar temas de importância como o uso de água como solvente e a separação de isômeros num curto espaço de tempo com base na solubilidade diferencial dos fenolatos formados. Por ser uma reação muito rápida dá tempo ao professor para discutir com os alunos os métodos de separação cromatográfica empregados e a técnica de ressonância magnética nuclear na identificação dos isômeros 3 e 5-nitro-salicilaldeídos.

\section{MATERIAL SUPLEMENTAR}

Está disponível em http://quimicanova.sbq.org.br, na forma de arquivo .PDF, com acesso livre.

\section{AGRADECIMENTOS}

À Profa. L. M. Lima e à pós-doutoranda C. M. de S. Menezes pela orientação na manipulação do programa simulador de pKa de moléculas (Moka pKa) e ao CNPq, à CAPES e FAPERJ pelo apoio financeiro.

\section{REFERÊNCIAS}

1. Sanseverino, A. M.; Quim. Nova 2002, 25, 660.

2. Buffer, C. R.; Microwave cooking and processing: Engineering fundamentals for the food scientist, Ed Chapman \& Hal: Londres, 1993.

3. Wathey, B.; Tierney, J.; Lidström, P.; Westman, J.; Drug Discovery Today 2002, 7, 373.

4. Lidström, P.; Tierney, J.; Wathey, B.; Westman, J.; Tetrahedron 2001, 57, 9225.

5. Kappe, C. O.; Chem. Soc. Rev. 2008, 37, 1127.

6. www.fisica.ucb.br/sites/000/74/00000098.pdf, acessada em Julho 2010.

7. Rosini, F.; Nascente, C. C.; Nóbrega, J. A.; Quim. Nova 2004, 27, 1012.

8. Gedye, R.; Smith, F.; Westaway K.; Ali, H.; Baldisera, L.; Laberge, L.; Rousell, J.; Tetrahedron Lett. 1986, 27, 279.

9. Giguere, R. J.; Bray, T. L.; Duncan, S. M.; Majetich, G.; Tetrahedron Lett. 1986, 27, 4945.

10. Kremsner, J. M.; Kappe, C. O.; J. Org. Chem. 2006, 71, 4651.

11. Bose, A. K.; Manhas, M. S.; Ghosh, M.; Shah, M.; Raju, V. S.; Bari, S. S.; Newaz, S. N.; Banik, B. K.; Chaudhary, A. G.; Barakat, K. J.; J. Org. Chem. 1991, 56, 6968.

12. La Hoz, A.; Diaz-Ortiz, A.; Moreno, A.; Chem. Soc. Rev. 2005, 34, 164.

13. Banik, B. K.; Barakat, K. J.; Wagle, D. R.; Manhas, M. S.; Bose, A. K.; J. Org. Chem. 1999, 64, 5746

14. Kappe, C. O.; Dallinger, D.; Mol. Diversity 2009, 13, 71.

15. Imamura, P. M.; Baptistella, L. H. B.; Quim. Nova 2000, 23, 270.

16. Cardoso, S. P.; Carneiro, J. W. M.; Quim. Nova 2001, 24, 381.

17. Bahulayayan, D.; Narayan, G.; Sreekumar, V.; Lalithambika, M.; Synth. Commun. 2002, 32, 3565.

18. Dallinger, D.; Kappe, C. O.; Chem. Rev. 2007, 107, 2563.

19. Geris, R.; dos Santos, N. A. C.; Amaral, B. A.; Maia, I. S.; Castro, V. D.; Carvalho, J. R. M.; Quim. Nova 2007, 30, 1369; Bastos, R. S.; da Cunha, A. S.; da Silva, L. C.; de Oliveira, C. C. P.; Rezende, C. M.; Pinto, A. C.; Quim. Nova 2008, 31, 172; Dias, A. G.; Pereira, F. M. A.; Soares, R. O.; Quim. Nova 2008, 31, 1885; dos Santos, A. P. B.; Gonçalves, I. R. C.; Pais, K. C.; Martinez, S. T.; Lachter, E. R.; Pinto, A. C.; Quim. Nova 2009, 32, 1667.

20. West, R. C.; Handbook of Chemistry and Physics, $49^{\text {th }}$ ed., Cranwood Parkway: Cleveland, 1968-1969.

21. Bose, A. K.; Ganguly, S. N.; Manhas, M. S.; He, W.; Speck, J.; Tetrahedron Lett. 2006, 47, 3213.

22. von Miller, W.; Chem. Ber. 1887, 20, 1927.

23. Barros Neto, B.; Scarminio, I. S.; Bruns, R. E.; Como fazer experimentos, $3^{\text {a }}$ ed., Ed. da Unicamp: Campinas, 2007. 


\section{O USO DE APARELHOS DE MICRO-ONDAS DOMÉSTICOS EM AULAS EXPERIMENTAIS DE QUÍMICA} ORGÂNICA: NITRAÇÃO DE SALICILALDEÍDO

Eurídes Francisco Teixeira, Ana Paula Bernardo dos Santos*, Renato Saldanha Bastos e Angelo C. Pinto

Departamento de Química Orgânica, Instituto de Química, B1. A, Centro de Tecnologia, Cidade Universitária, Universidade Federal do Rio de Janeiro, 21949-900 Rio de Janeiro - RJ, Brasil

Arthur Eugen Kümmerle

Departamento de Fármacos, Faculdade de Farmácia, Cidade Universitária, Universidade Federal do Rio de Janeiro, 21941-902

Rio de Janeiro - RJ, Brasil

Roberto Rodrigues Coelho

Centro de Tecnologia Mineral, Cidade Universitária, Universidade Federal do Rio de Janeiro, 21941-590 Rio de Janeiro - RJ, Brasil

\section{MATERIAL SUPLEMENTAR}

\section{Determinação da potência do micro-ondas}

Devido às diferenças de especificação com relação à potência dos fornos de micro-ondas comerciais, o primeiro passo consistiu no ajuste do tempo e da potência do micro-ondas. ${ }^{22}$ Porém, em função das diferenças de distribuição da irradiação das micro-ondas dentro do aparelho, inicialmente determinou-se a região mais quente através da irradiação de um papel de fax no nível 10 (máximo) por 60 s. A região mais escura no papel indicou o ponto onde incidiu a maior irradiação das micro-ondas.

$\mathrm{O}$ aumento da temperatura de uma determinada massa de água é diretamente proporcional à incidência de radiação micro-ondas e por meio da variação de temperatura, pode-se calcular a potência do forno micro-ondas nos diferentes níveis segundo a Equação $1{ }^{7}$

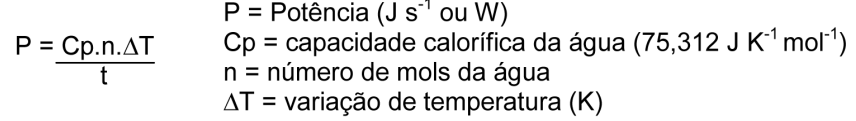

A Figura 1S ilustra as potências experimentais obtidas no aquecimento de $500 \mathrm{~g}$ de água por $60 \mathrm{~s}$ para os diferentes níveis de potência do aparelho. Por medidas de segurança, a potência experimental de um aparelho de micro-ondas doméstico não segue o modelo linear. Esta curva foi obtida para o aparelho utilizado no experimento com o objetivo de determinar a potência de trabalho.

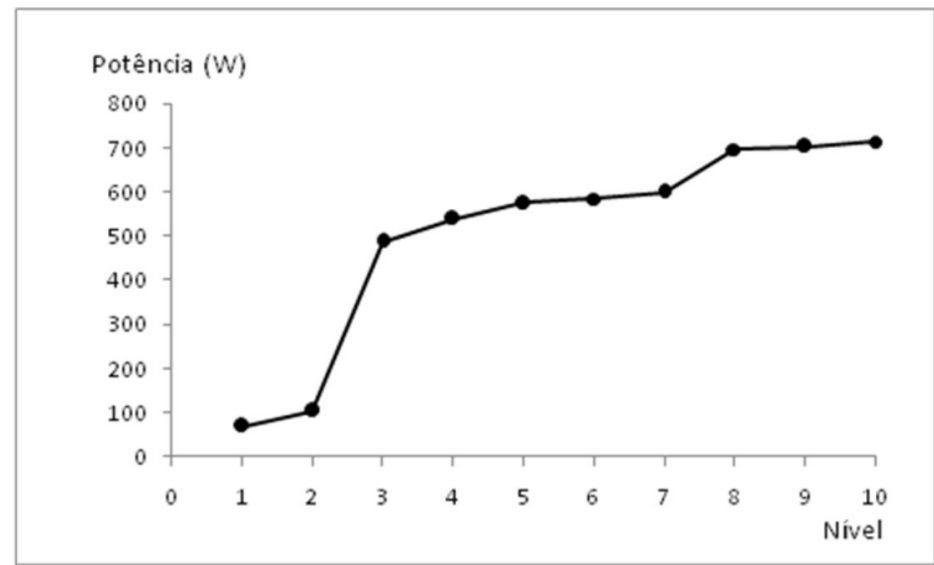

Figura 1S. Potências das micro-ondas em função dos níveis do aparelho 


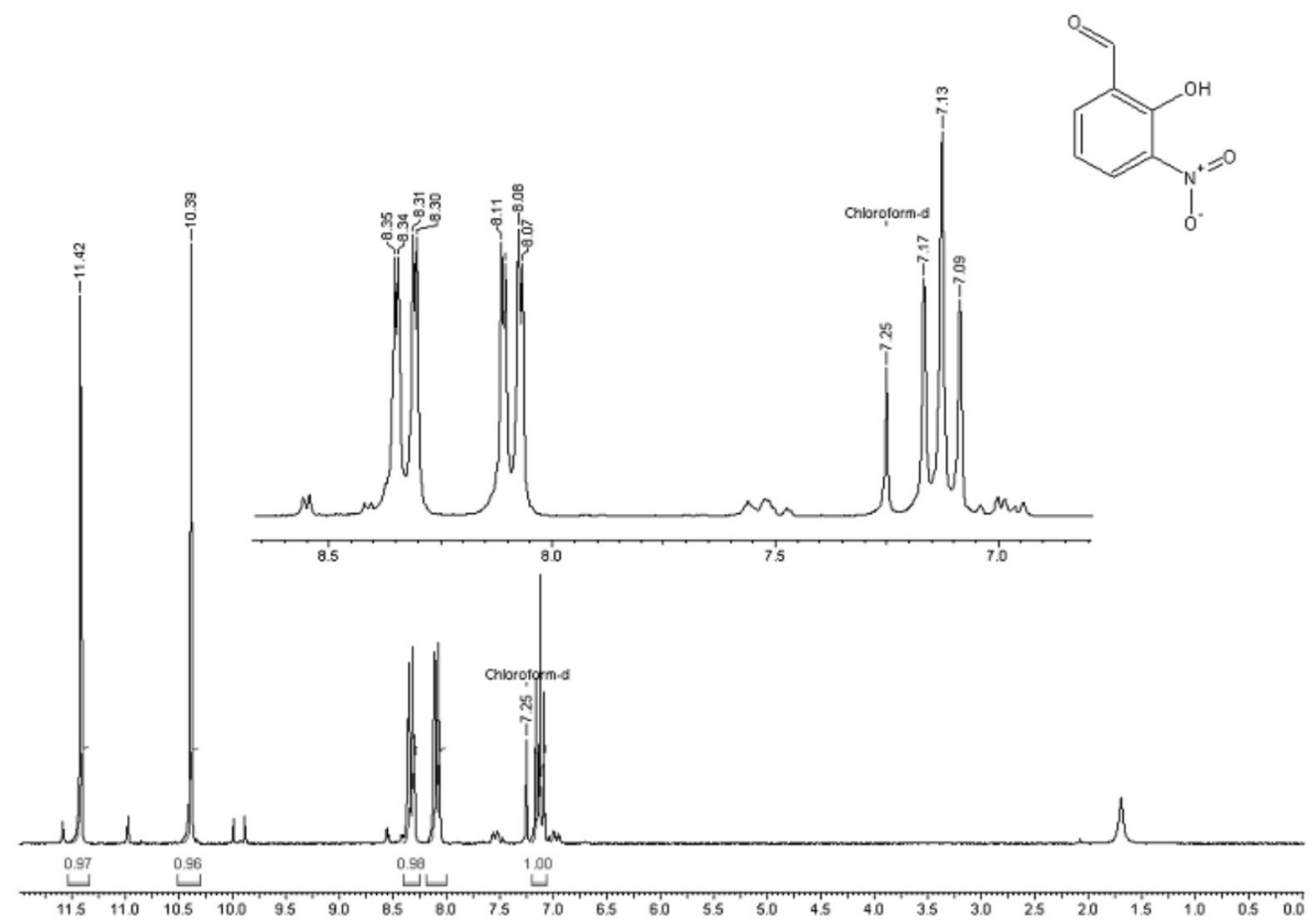

Figura 2S. $\mathrm{RMN} \mathrm{H} \mathrm{H}^{l}$ do 3-nitro-salicilaldeído $\left(\mathrm{CDCl}_{3}\right)$

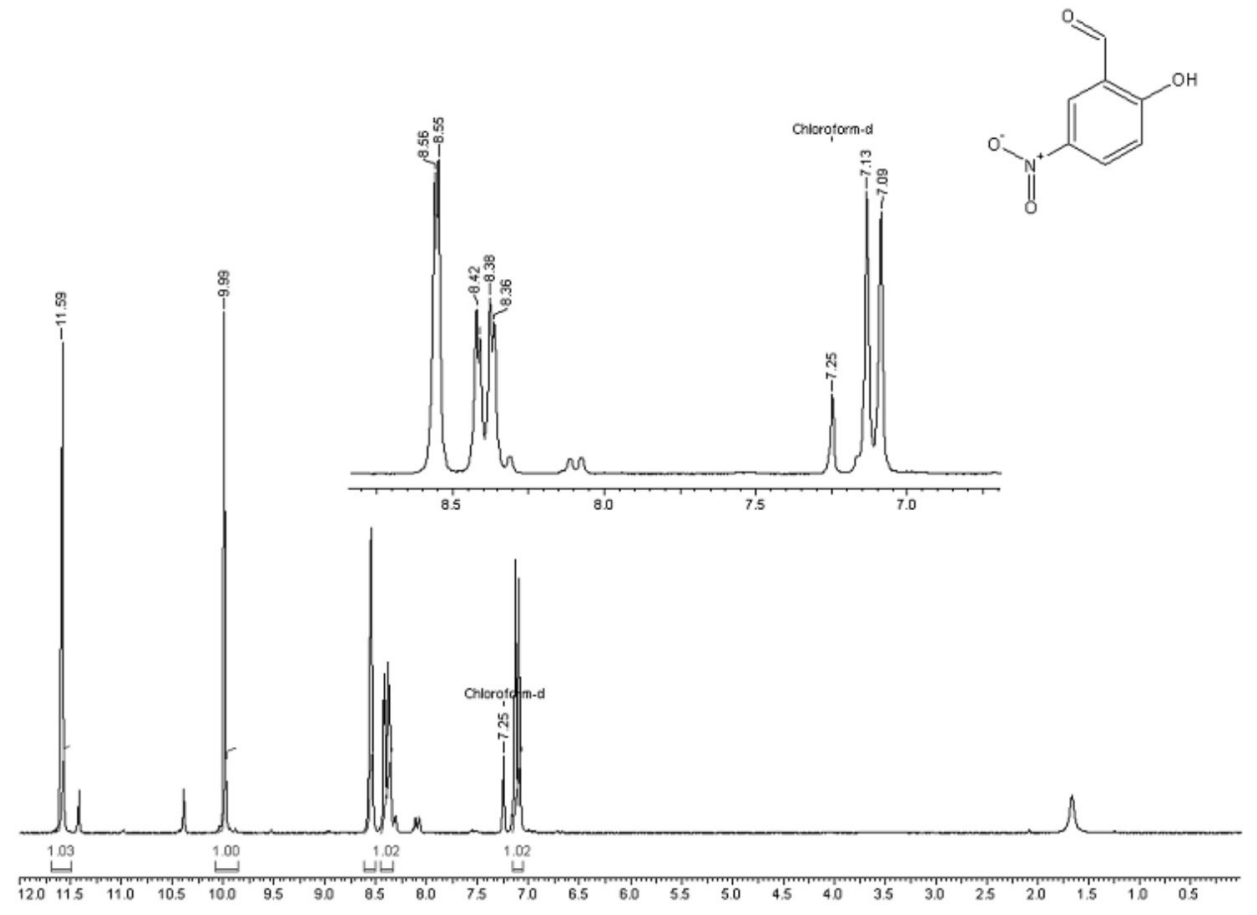

Figura 3S. $\mathrm{RMN} \mathrm{H} \mathrm{H}^{l}$ do 5-nitro-salicilaldeído $\left(\mathrm{CDCl}_{3}\right)$ 


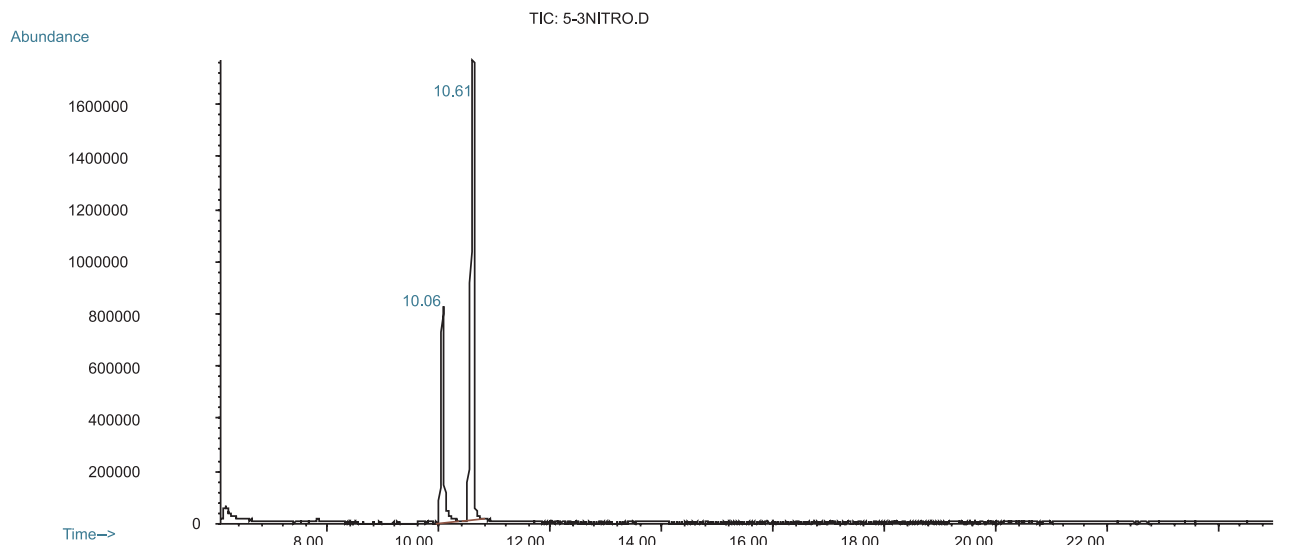

Figura 4S. Cromatograma da mistura bruta dos isômeros 3 (10,06 min) e 5-nitro-salicilaldeído (10,61 min)

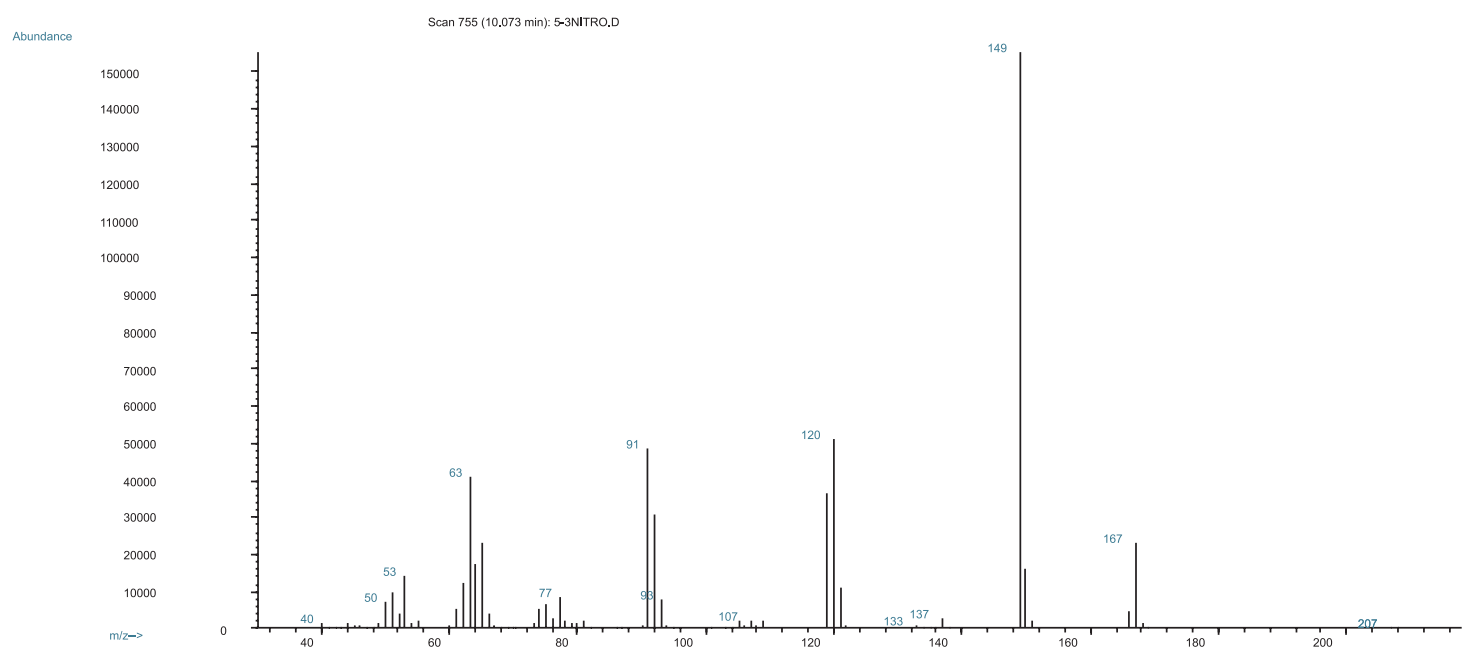

Figura 5S. Espectro de massas de 3-nitro-salicilaldeído

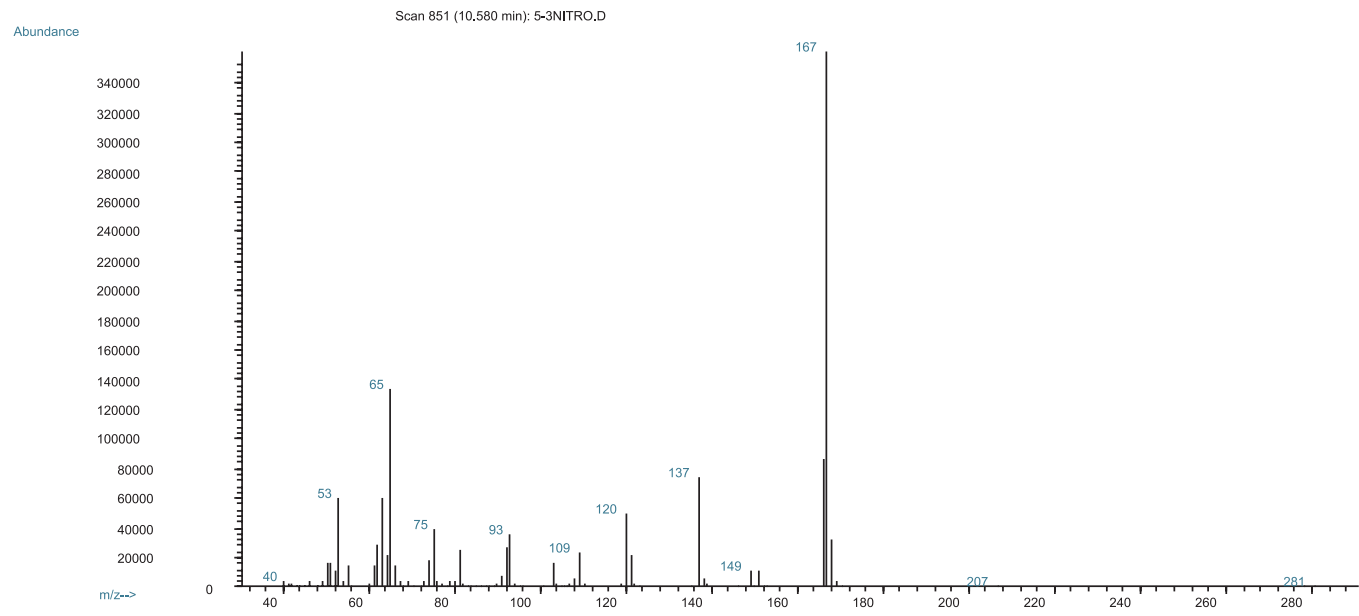

Figura 6S. Espectro de massas de 5-nitro-salicilaldeído 


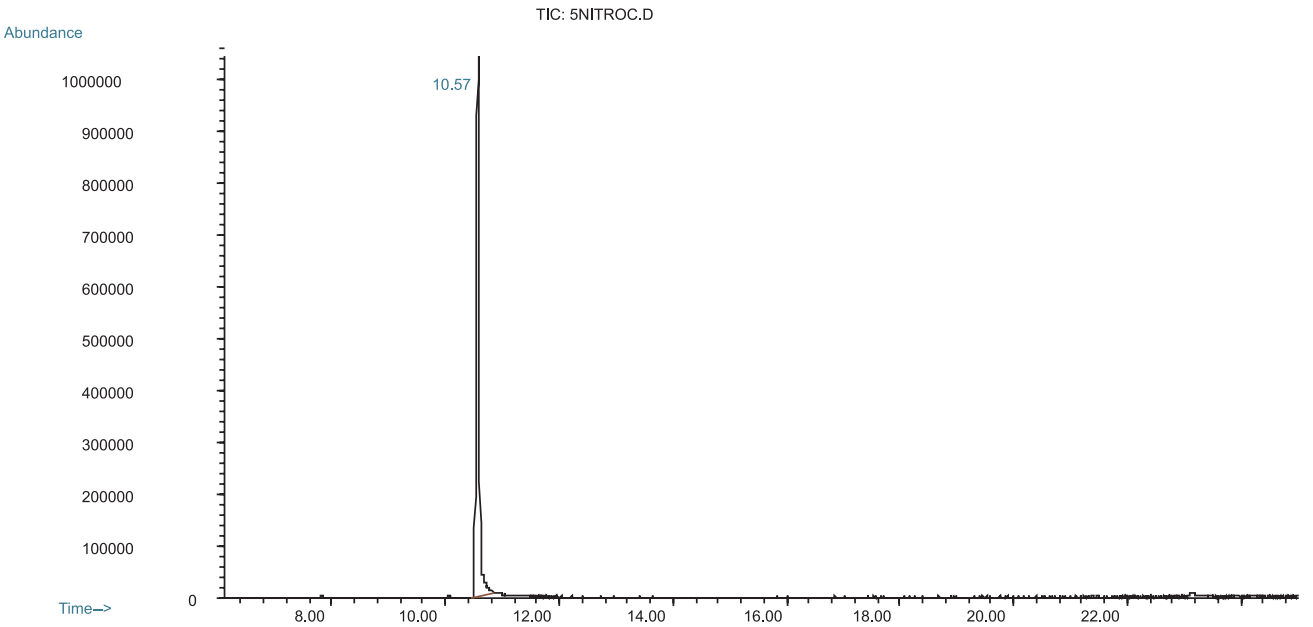

Figura 7S. Cromatograma do 5-nitro-salicilaldeído após isolamento 